\title{
Progress and prospects of biomarkers in primary liver cancer (Review)
}

\author{
YU-XUE GAO ${ }^{1,2}$, TONG-WANG YANG ${ }^{1,2}$, JI-MING YIN $^{1}$, PENG-XIANG YANG ${ }^{2}$, \\ BU-XIN KOU ${ }^{1}$, MENG-YIN CHAI ${ }^{1}$, XIAO-NI LIU ${ }^{1}$ and DE-XI CHEN ${ }^{1,2}$ \\ ${ }^{1}$ Beijing Institute of Hepatology, Beijing Youan Hospital, Capital Medical University, Beijing 100069; \\ ${ }^{2}$ Organ Transplantation Center, The Affiliated Hospital of Qingdao University, Qingdao, Shandong 266003, P.R. China
}

Received October 16, 2019; Accepted February 17, 2020

DOI: 10.3892/ijo.2020.5035

\begin{abstract}
Tumor biomarkers are important in the early screening, diagnosis, therapeutic evaluation, recurrence and prognosis prediction of tumors. Primary liver cancer is one of the most common malignant tumors; it has high incidence and mortality rates and seriously endangers human health. The main pathological types of primary liver cancer include hepatocellular carcinoma (HCC), intrahepatic cholangiocarcinoma (ICC) and combined HCC-cholangiocarcinoma (cHCC-CC). In the present review, a systematic outline of the current biomarkers of primary liver cancer is presented, from conventional blood biomarkers, histochemical biomarkers and potential biomarkers to resistance-associated biomarkers. The important relationships are deeply elucidated between biomarkers and diagnosis, prognosis, clinicopathological features and resistance, as well as their clinical significance, in patients with the three main types of primary liver cancer. Moreover, a summary of several important biomarker signaling pathways is provided, which is helpful for studying the biological mechanism of liver cancer. The purpose of this review is to provide help for clinical or medical researchers in the early diagnosis, differential diagnosis, prognosis and treatment of HCC.
\end{abstract}

\section{Contents}

1. Introduction

2. Blood biomarkers

3. Histochemical biomarkers

Correspondence to: Professor Xiao-Ni Liu or Professor De-Xi Chen, Beijing Institute of Hepatology, Beijing Youan Hospital, Capital Medical University, 10 Xi Tou Tiao, You An Men Wai, Fengtai, Beijing 100069, P.R. China

E-mail:1xnlxm@126.com

E-mail: dexichen@ccmu.edu.cn

Key words: hepatocellular carcinoma, intrahepatic cholangiocarcinoma, combined hepatocellular carcinoma-cholangiocarcinoma, biomarker, cell signaling, drug resistance
4. Potential biomarkers

5. Resistance-associated biomarkers

6. Biomarker-associated signaling pathways

7. Conclusions

\section{Introduction}

Primary liver cancer is a common tumor worldwide, with a high incidence and mortality, and is a frequent cause of cancer death. Primary liver cancer mainly includes hepatocellular carcinoma (HCC), intrahepatic cholangiocarcinoma (ICC) and combined HCC-cholangiocarcinoma (cHCC-CC), with incidences of 75-85, $10-15$ and $1-4.7 \%$, respectively worldwide $(1,2)$. HCC is a malignant tumor that originates from hepatocytes and is the fifth most common cancer and the third leading cause of cancer-associated deaths (3). ICC, the second most common primary liver tumor, is a malignant tumor that originates from the biliary epithelium (4). cHCC-CC is a rare type of primary hepatic carcinoma that has the characteristics of bi-directional differentiation of hepatocytes and bile duct epithelial cells $(2,5)$. Although these cancers have different biological behaviours, it is sometimes difficult to distinguish them by their biological characteristics. Therefore, the laboratory detection of liver cancer biomarkers, such as blood biomarkers and histochemical biomarkers, plays an important role in the early monitoring, pathological classification, treatment options and prognosis of patients with primary liver cancer. The most widely used biomarker of primary liver cancer worldwide is $\alpha$-fetoprotein (AFP); however, its sensitivity and specificity are not very satisfactory $(3,4)$. It is of great significance for the diagnosis, treatment effect observation and prognosis judgement of primary liver cancer to combine different tumor biomarkers according to different clinical conditions, and to develop new biomarkers. In the present review, current clinical and experimental studies have been summarized to highlight the progress in biomarkers, as well as some new promising biomarkers, for clinical and medical research to diagnose and guide the therapy of primary liver cancer.

\section{Blood biomarkers}

Blood biomarkers are of great significance in the early diagnosis of liver cancer and mainly include categories related to 
proteins, cytokines, enzymes and isoenzymes as well as transcripts of associated genes (Table I). Regardless of the diverse acknowledged molecular indicators in liver cancer, each of them alone cannot be a specific biomarker in different types of liver cancer, and their combined application is important for the identification of liver cancer types.

AFP and AFP-L3. AFP is a $\sim 70 \mathrm{kDa}$ glycoprotein molecule consisting of 591 amino acids that is derived from fetal hepatocytes and the yolk sac. As a useful biomarker of liver cancer, AFP has been widely used in its diagnosis. However, AFP may also increase in hepatitis, liver cirrhosis and liver injury, especially in 10-20\% of early-stage HCCs with elevated AFP-L3 levels (6). Moreover, serum AFP levels are not largely elevated in the $80 \%$ of HCC patients with small tumor sizes; the sensitivity of AFP in patients with HCC has been reported to be $52 \%$ for tumors $>3 \mathrm{~cm}$ in diameter but only $25 \%$ for tumors $<3 \mathrm{~cm}$ in diameter (3). The use of AFP in combination with a variety of serum biomarkers contributes to the early diagnosis of HCC, and can improve sensitivity and specificity compared with single use (3). AFP levels are not significantly changed in patients with ICC and, therefore, AFP may serve as a powerful biomarker to distinguish ICC from HCC (4). In one study, elevated serum AFP levels (>20 ng/ml) were detected in $58.3 \%$ of patients with cHCC-CC, which was slightly lower than that in patients with HCC (66.5\%) and significantly higher than that in patients with ICC (13.7\%) (5). Another study detected the elevation of AFP in $62.2 \%(28 / 45)$ of patients with $\mathrm{cHCC}-\mathrm{CC}$ (7).

Due to the low specificity and sensitivity of AFP, other biomarkers are required to assist the diagnosis. AFP-L3 is a heteroplast of AFP, which is only derived from tumor tissue and is a specific biomarker for HCC. Clinical studies revealed a specificity of $90-95 \%$ and a sensitivity of $~ 51 \%$ for AFP-L3 in early-stage HCC detection (8). The AFP-L3 fraction is more sensitive than AFP for small-sized tumors or for patients with early-stage HCC, is highly specific for HCC and reflects tumor features such as poor differentiation or malignant invasion $(9,10)$. AFP-L3 may serve as a supplementary test variable to improve the diagnostic value of $\mathrm{HCC}$ detection in patients with relatively low AFP levels (9). The specificity and sensitivity of a combination of AFP and AFP-L3 were found to be 79 and $87 \%$, respectively, in the diagnosis of HCC (11). Serum AFP-L3 levels and the percentage of AFP-L3 in total AFP (AFP-L3\%) can be efficiently applied to distinguish HCC from benign liver diseases and to diagnose HCC early in the clinic (12). The sensitivity of AFP-L3\% has been reported to be $35-45 \%$ for HCC tumors with a diameter $<2 \mathrm{~cm}$, and $80-90 \%$ for HCC tumors with a diameter $>5 \mathrm{~cm}$, respectively, with variation according to clinical features (13).

Des- $\gamma$-carboxyprothrombin $(D C P)$. DCP is a new serological biomarker of $\mathrm{HCC}$, which is also known as prothrombin-induced by vitamin $\mathrm{K}$ absence-II, and is produced in HCC cells due to a defect in the carboxylation of the prothrombin precursor after translation and is elevated in patients with $\operatorname{HCC}(14,15)$. In one study, DCP exhibited higher sensitivity than AFP; the sensitivity and specificity of DCP were 85 and $75 \%$, respectively (15). In another study, DCP exhibited significantly improved results compared with AFP and AFP-L3 in the diagnosis of $\mathrm{HCC}$, with sensitivity and specificity up to 86 and 93\%, respectively, for distinguishing HCC from cirrhosis (16). DCP has served as an effective biomarker for the diagnosis of HCC in Japan, South Korea and India, particularly for judging intrahepatic metastasis and prognosis (17). Studies have demonstrated that elevated DCP levels are indicative of larger tumor size, greater tumor numbers, a later clinical phase, bile duct invasion, vascular invasion and a shorter median survival time $(14,18)$. A meta-analysis suggested that DCP should serve as an indicator of $\mathrm{HCC}$ in the established guidelines of other countries and regions, especially those with a high incidence of hepatitis B virus (HBV) infections, such as East Asia (with the exception of Japan) and Africa (19). A combination of DCP and AFP enhanced the sensitivity of HCC diagnosis to $>80$ and $70 \%$, respectively, in tumors $3-4$ and $2-3 \mathrm{~cm}$ in diameter (20).

$\alpha$-L-fucosidase (AFU). AFU is characterized as a lysosomal enzyme in all mammalian cells, enabling the degradation of a variety of fucose-containing fuco-glycoconjugates $(21,22)$. AFU has been demonstrated to serve as a useful biomarker for HCC, and the serum level of AFU in patients with HCC has been found to be higher than that in patients with benign hepatic diseases (23). AFU is considered as an earlier biomarker, able to diagnose $85 \%$ of patients with HCC 6 months prior to detection by ultrasonography (24). Serum AFU activity can return to normal after liver transplantation and successful intervention for HCC, while AFU is also elevated with the recurrence of HCC; therefore, AFU can serve as a follow-up biomarker for patients with HCC (21). The preoperative AFU level has been suggested to be powerful in the prediction of tumor recurrence and mortality in HCC patients with low levels of AFP (21). The AFU level is positively associated with tumor size in patients with HCC and can be combined with AFP for the early diagnosis of HCC (8).

Golgi protein 73 (GP73). GP73 is a transmembrane glycoprotein of resident Golgi type II, with a molecular mass of $\sim 70 \mathrm{kDa}$, and is expressed mainly in the epithelial cells of numerous human tissues (25). GP73 is hardly expressed in healthy subjects, but its expression is moderately increased in patients with cirrhosis and viral infection, and markedly increased in patients with HCC (25-27). A study reported that the sensitivity and specificity of GP73 for HCC were 74.6 and $97.4 \%$, respectively, markedly higher in comparison with 58.2 and $85.3 \%$ for AFP (28). Another study revealed that the sensitivity and specificity of serum GP73 were each 95\% for Egyptian patients with early HCC, and also suggested that GP73 was superior to AFP for the early diagnosis and examination of HCC (29). Furthermore, GP73 has been shown to be a powerful biomarker with a sensitivity, specificity and accuracy of $66,96.2$ and $84.6 \%$, respectively, for the diagnosis of small HCC with negative AFP, which supports its potential contribution to the diagnosis of small HCC (30).

Osteopontin (OPN). OPN is a highly modified, phosphorylated and glycosylated protein of extracellular matrix that binds to integrin and is expressed in a variety of cells, such as those of the immune system, epithelial tissues, smooth muscle cells, osteoblasts and tumors $(31,32)$. In one study, the prevalence of autoantibodies against OPN was found to be 12.8, 15.6 and 


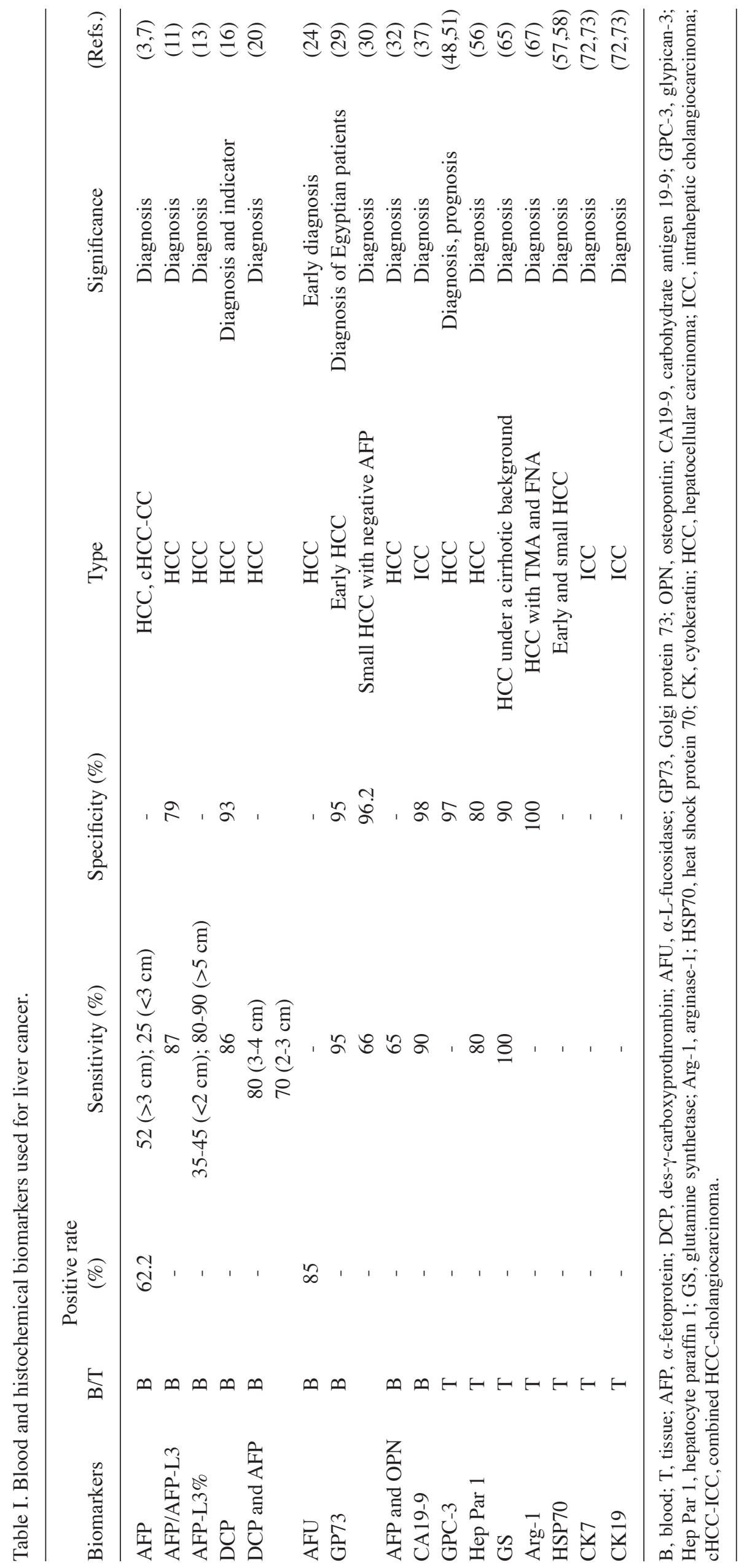


$3.1 \%$ in the serum of patients with $\mathrm{HCC}$, liver cirrhosis and chronic hepatitis, respectively, compared with $0 \%$ in the serum of healthy individuals, and when OPN was combined with AFP to diagnose HCC, the sensitivity increased to $65 \%$ (32). In another study, OPN levels were shown to be much higher in patients with hepatitis $\mathrm{C}$ virus-associated HCC compared with healthy subjects and patients with chronic liver diseases (33). Furthermore, levels of serum OPN were found to be elevated a year prior to HCC diagnosis, with OPN indicated to be superior to AFP in differentiating cases of HCC from those of liver cirrhosis (33). A study using an OPN-knockout HCC mouse model revealed that OPN induced chemotactic migration, alternatively activated macrophages, increased tumor-associated macrophage infiltration and upregulated the expression of programmed death ligand 1 in HCC through activation of the colony stimulating factor-1 (CSF1)-CSF1 receptor pathway in macrophages (34). OPN may also be considered for use in the monitoring of microvascular invasion in chronic hepatitis B (CHB)-associated HCC, as it has been found to be upregulated in patients who did not receive antiviral therapy compared with antiviral-treated patients, and exhibited an association with tumor aggressiveness and poor prognosis (35).

Carbohydrate antigen 19-9 (CA19-9). CA19-9 was originally identified in the culture medium of a human colorectal cancer cell line and is widely used to diagnose various adenocarcinomas, including cholangiocarcinoma (36); it is a significant serological biomarker in ICC. A study revealed that the sensitivity and specificity continuously increased with increasing CA19-9 serum concentration; when the serum level of CA19-9 was $>632 \mathrm{U} / \mathrm{ml}$, its sensitivity and specificity were 90.0 and $98.0 \%$, respectively (37). In addition, the preoperative CA19-9 level can serve as an independent prognostic factor in patients with ICC (38). A study demonstrated that preoperative serum CA19-9 levels may be used to predict lymph node metastasis in patients with ICC (39).

At present, the triple detection of DCP, AFP and AFP-L3\% is a common serum biomarker combination for the early diagnosis of $\mathrm{HCC}$. The detection rate of $\mathrm{HCC}$ can be increased to $85.9 \%$ by the combined detection of these three biomarkers (40). In the prognostic evaluation of $\mathrm{HCC}$, the higher the AFP, AFP-L3\% and DCP levels, the lower the survival rate and the higher the recurrence rate (40). The increase in the three biomarkers is associated with the invasiveness of the tumors (40). DCP and AFP-L3\% are positively associated with the size and stage of the tumors (40). A triple examination of cancer using DCP, AFP and AFP-L3\% is helpful for the differential diagnosis of intrahepatic nodules. Authoritative guidelines and consensus, such as those of the Asia-Pacific Society of Hepatology (41), the Japan Society of Hepatology (42), Guidelines for the Prevention, Care and Treatment of Persons with Chronic Hepatitis B Infection (2015) (43) and Guidelines for Diagnosis and Treatment of Primary Liver Cancer in China (2017) (44), recommend DCP, AFP and AFP-L3\% for the screening of high-risk populations, the auxiliary diagnosis of liver cancer, the monitoring of therapeutic effect and as a predictor of prognosis and recurrence. In conclusion, AFP is of great value in the diagnosis and prognosis evaluation of HCC. DCP and AFP-L3, as classical serological indicators in the diagnosis of HCC, are complementary to AFP.

\section{Histochemical biomarkers}

Pathological diagnosis is the gold standard of primary liver cancer, whose main detection methods include hematoxylin and eosin (H\&E) staining and immunohistochemistry (IHC). Tissue biomarkers are the true reflection of tumor tissue structure and cell morphology, and are more objective and accurate than various imaging examinations and chemical examinations (Table I). Therefore, tissue biomarkers serve an important role in the diagnosis, differential diagnosis, treatment and prognosis of patients with benign tumors, HCC, ICC and cHCC-CC (Table II).

Glypican-3 (GPC-3). GPC-3 is a membrane-bound heparan sulfate proteoglycan that belongs to the glypican family; it has an amino terminal protein and a membrane-bound carboxyl terminal protein $(45,46)$. GPC-3 anchors at the glycosylphosphatidylinositol of the membrane by the C-terminus; can be enzymatically lysed, releasing a soluble form of GPC-3; and is released into the serum by a lipase called notum (46) (Fig. 1). GPC-3 is overexpressed in up to $80 \%$ of patients with HCC and is able to distinguish HCC from ICC and other malignant tumors (47). GPC-3 is a promising biomarker for HCC with a specificity of up to $97 \%$; it modulates cell-cycle progression, and promotes cellular migration and invasiveness in HCC cell lines $(48,49)$. GPC-3 is specifically expressed in the HCC tumor tissue and is widely used to distinguish HCC from ICC. GPC-3 expression is associated with differentiation grade, and exhibits higher expression in moderately differentiated and poorly differentiated HCC than in well-differentiated HCC (47). A study revealed that GPC-3 is overexpressed in $\mathrm{HCC}$ tissue and can serve as a sensitive and specific biomarker to diagnose early HCC (50). Clinicopathological analysis demonstrated that the overexpression of GPC-3 was associated with poor postoperative disease-free survival and overall survival (OS) and that it was an independent risk factor (51). GPC-3 is associated with HBV infection, TNM stage, periportal cancerous embolus and extrahepatic metastasis, and can serve as a prognostic factor (51). GPC-3 is not only a powerful histochemical biomarker but also a serological biomarker. A study showed that the serum GPC-3 level was $>300 \mathrm{ng} / \mathrm{l}$ in $50 \%$ of early HCC patients, although their serum AFP level was $<100 \mu \mathrm{g} / 1$, revealing that the serum GPC-3 level can be used to monitor early HCC and may serve a role in the diagnosis of HCC (24). Recently, a simple 2D imaging probe with minimal background fluorescence and high binding affinity for GPC-3 was developed, which has been shown to sensitively and selectively image HCC cells and a normal cell line overexpressing GPC-3, as well as to effectively differentiate between HCC-positive and para-carcinoma tissue regions (52).

Hepatocyte paraffin 1 (Hep Par 1). Hep Par 1 was first identified in a formalin-fixed failed allograft liver and is a monoclonal antibody that is highly sensitive and specific for hepatocellular differentiation (53-55). Hep Par 1 is a mitochondrial urea cycle antigen associated with mitochondrial antigens from malignant and non-malignant hepatic 
Table II. Histochemical biomarkers with clinicopathological associations.

\begin{tabular}{|c|c|c|c|c|}
\hline Biomarkers & Type & Expression level & Associations & (Refs.) \\
\hline GPC-3 & $\mathrm{HCC}$ & High & $\begin{array}{l}\text { Cell-cycle, migration, invasiveness, differentia } \\
\text { tion grade, HBV infection, TNM stage, periportal } \\
\text { cancerous embolus, extrahepatic metastasis, poor } \\
\text { postoperative DFS and OS }\end{array}$ & $(47-49,51)$ \\
\hline Hep Par 1 & $\mathrm{HCC}$ & High & Hepatocellular differentiation & $(53-55)$ \\
\hline HSP70 & $\begin{array}{l}\text { Small and early } \\
\mathrm{HCC}\end{array}$ & High & $\begin{array}{l}\text { Vascular invasion, high stage, low grade, poor } \\
\text { differentiation, cell proliferation, lymph node } \\
\text { metastasis, high Ki-67 index and larger tumor } \\
\text { size and portal vein invasion }\end{array}$ & $(58-60)$ \\
\hline GS & $\mathrm{HCC}$ & High & $\begin{array}{l}\beta \text {-catenin gene mutations, higher recurrence and } \\
\text { lower survival }\end{array}$ & $(63)$ \\
\hline Arg-1 & $\mathrm{HCC}$ & High & Hepatocellular differentiation & $(69,70)$ \\
\hline CK7 & $\mathrm{ICC}$ & High & Aggressive tumor phenotypes and adverse OS & $(73)$ \\
\hline CK19 & ICC & High & Aggressive tumor phenotypes and adverse OS & $(73)$ \\
\hline $\begin{array}{l}\text { CK } 7 / \text { CK } 19 \\
\text { index }\end{array}$ & ICC & High & OS & (73) \\
\hline
\end{tabular}

GPC-3, glypican-3; Hep Par 1, hepatocyte paraffin 1; HSP70, heat shock protein 70; GS, glutamine synthetase; Arg-1, arginase-1; CK, cytokeratin; HCC, hepatocellular carcinoma; ICC, intrahepatic cholangiocarcinoma; HBV, hepatitis B virus; DFS, disease-free survival; OS, overall survival.

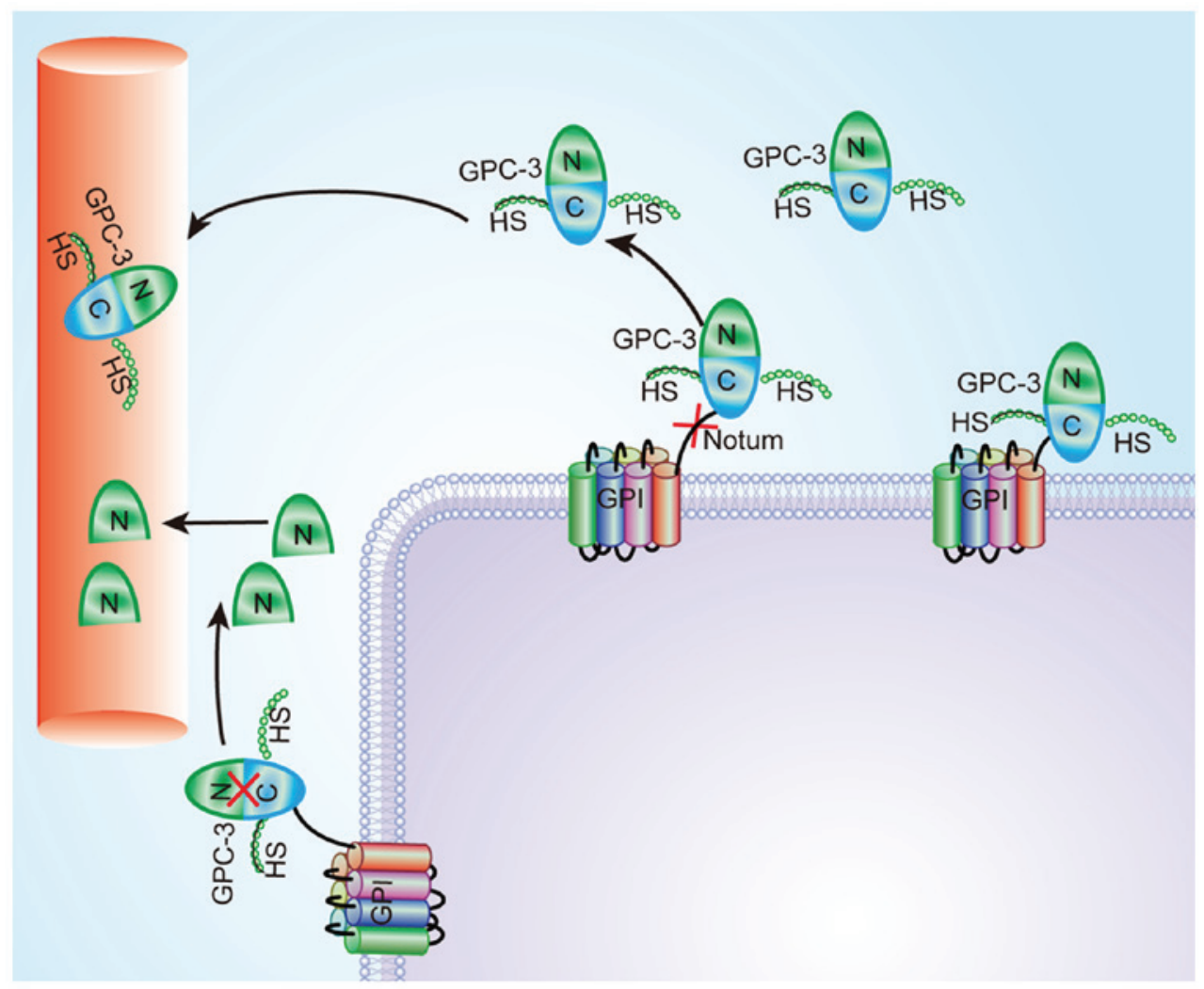

Figure 1. Secretion of GPC-3. GPC-3 is a membrane-bound HS proteoglycan that belongs to the glypican family; it anchors at the GPI of the membrane by the C-terminus; it can be enzymatically lysed, releasing a soluble form of GPC-3; and is released into the serum by the lipase Notum. GPC-3, glypican-3; HS, heparan sulfate; GPI, glycosylphosphatidylinositol.

cells (54). A study reported that the rate of Hep Par 1 expression was $100 \%$ in well-differentiated and moderately differentiated HCC (55). Another report revealed that Hep Par 1, whose sensitivity and specificity were both $80 \%$ in 
Table III. miRNA biomarkers used for liver cancer.

\begin{tabular}{|c|c|c|c|c|}
\hline Biomarkers & Type & Expression level & Associations & (Refs.) \\
\hline miR-21 and miR-10b & $\mathrm{HCC}$ & High & $\begin{array}{l}\text { Proliferation, migration, and invasion, advanced tumor } \\
\text { stage, HIF- } 1 \alpha / \text { HIF- } 2 \alpha \text { expression and disease-free survival }\end{array}$ & $(82)$ \\
\hline miR-122 & $\mathrm{HCC}$ & Low & AFP, ALT, AST and ALP levels, and tumor size & $(83)$ \\
\hline $\operatorname{miR}-224$ & $\mathrm{HCC}$ & High & AFP, ALT, AST, ALP levels and tumor size & $(83)$ \\
\hline $\operatorname{miR}-1204$ & $\mathrm{HCC}$ & High & $\begin{array}{l}\text { Proliferation, tumor growth, tumor size and advanced TNM } \\
\text { stage, inhibited apoptosis }\end{array}$ & $(84)$ \\
\hline hsa-miR-210 & $\mathrm{HCC}$ & High & $\begin{array}{l}\text { AFP level, pathological grade, TNM stage, tumor stage and } \\
\text { vascular invasion }\end{array}$ & $(85)$ \\
\hline miR-221 & $\mathrm{HCC}$ & High & $\begin{array}{l}\text { Clinical TNM stage, tumor capsular infiltration and poor. } \\
\text { prognosis }\end{array}$ & $(86)$ \\
\hline miR-191 & $\mathrm{ICC}$ & High & Proliferation, invasion and migration & $(87)$ \\
\hline $\operatorname{miR}-424-5 p$ & ICC & Low & Invasion and migration & $(88)$ \\
\hline
\end{tabular}

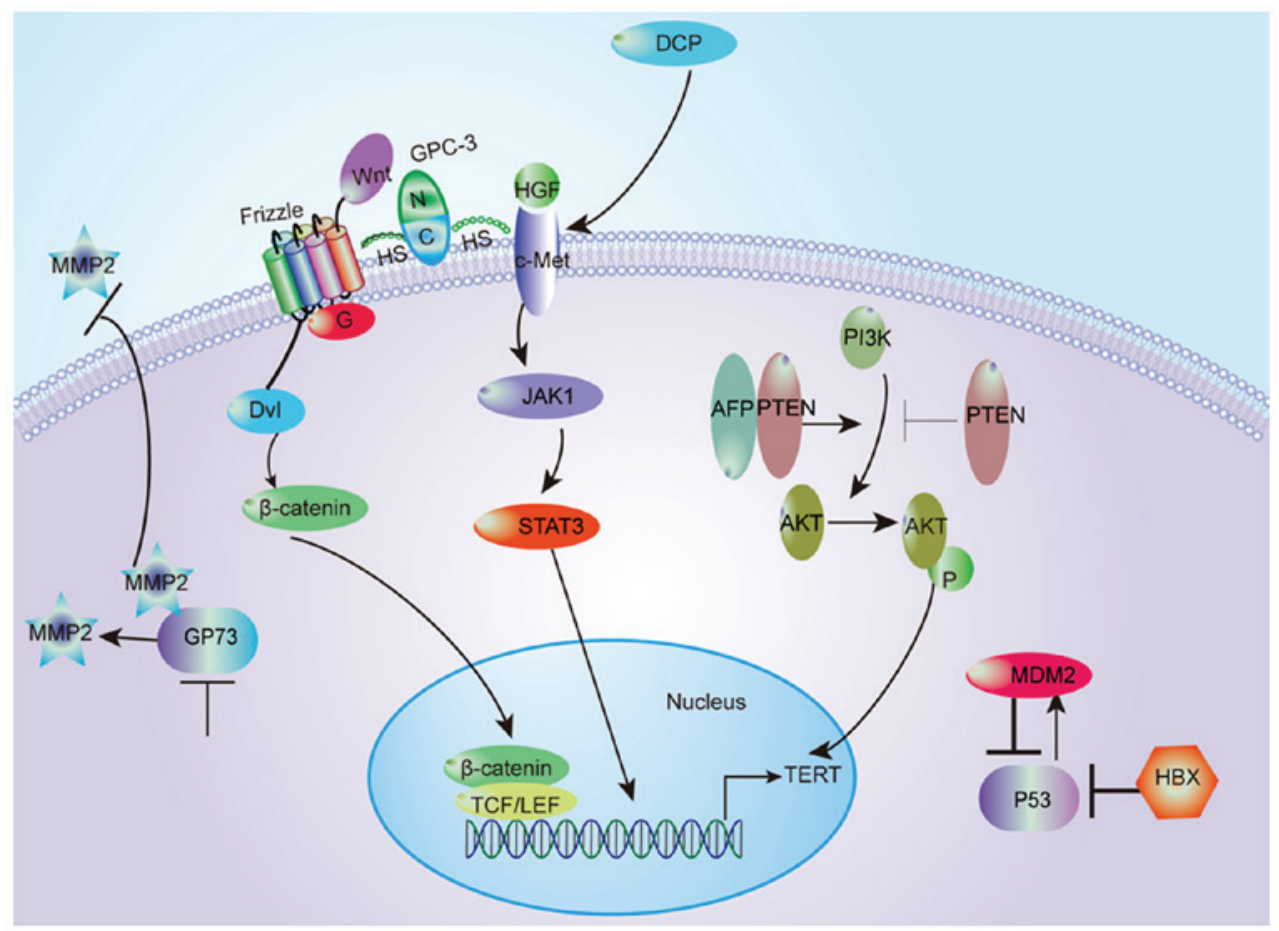

Figure 2. Biomarker-associated signaling pathways. GPC-3 can combine with Wnt to stimulate nuclear/cytoplasmic $\beta$-catenin. DCP activates the c-Met-Janus kinase 1-STAT3 kinase cascade. AFP interacts with PTEN to activate PI3K/AKT/mTOR signaling. PTEN downregulation also activates AKT. The dynamic balance between MDM2 and p53 is destroyed. The knockdown of GP73 suppresses the secretion of MMP2 by p53 signaling. GPC-3, glypican-3; DCP, des- $\gamma$-carboxyprothrombin; AFP, $\alpha$-fetoprotein; PTEN, phosphatase and tensin homologue deleted on chromosome 10; PI3K, phosphatidylinositol 3-kinase; MDM2, murine double minute 2; GP73, Golgi protein 73; MMP2, matrix metalloproteinase-2.

well-differentiated $\mathrm{HCC}$, was more likely to be negative in poorly differentiated and sclerosing HCC (56). Hep Par 1 was found to have low sensitivity in poorly differentiated HCC, and was not easily able to distinguish between HCC and adenocarcinoma (53). Therefore, Hep Par 1 can be combined with other biomarkers in morphologically difficult cases with poorly differentiated $\mathrm{HCC}$ and metastatic carcinoma of the liver to determine diagnoses.
Heat shock protein 70 (HSP70). HSP70 is a member of a highly conserved protein family, and is expressed at low levels under normal conditions but serves a significant role in response to heat shock, hypoxia, genotoxic agents and nutrient starvation $(57,58)$. HSP70 is a useful histochemical biomarker that is nucleocytoplasmic and mostly focally stained in HCC by IHC (57). Clinically, HSP70 is considered an indispensable biomarker that is significant clinically in distinguishing 


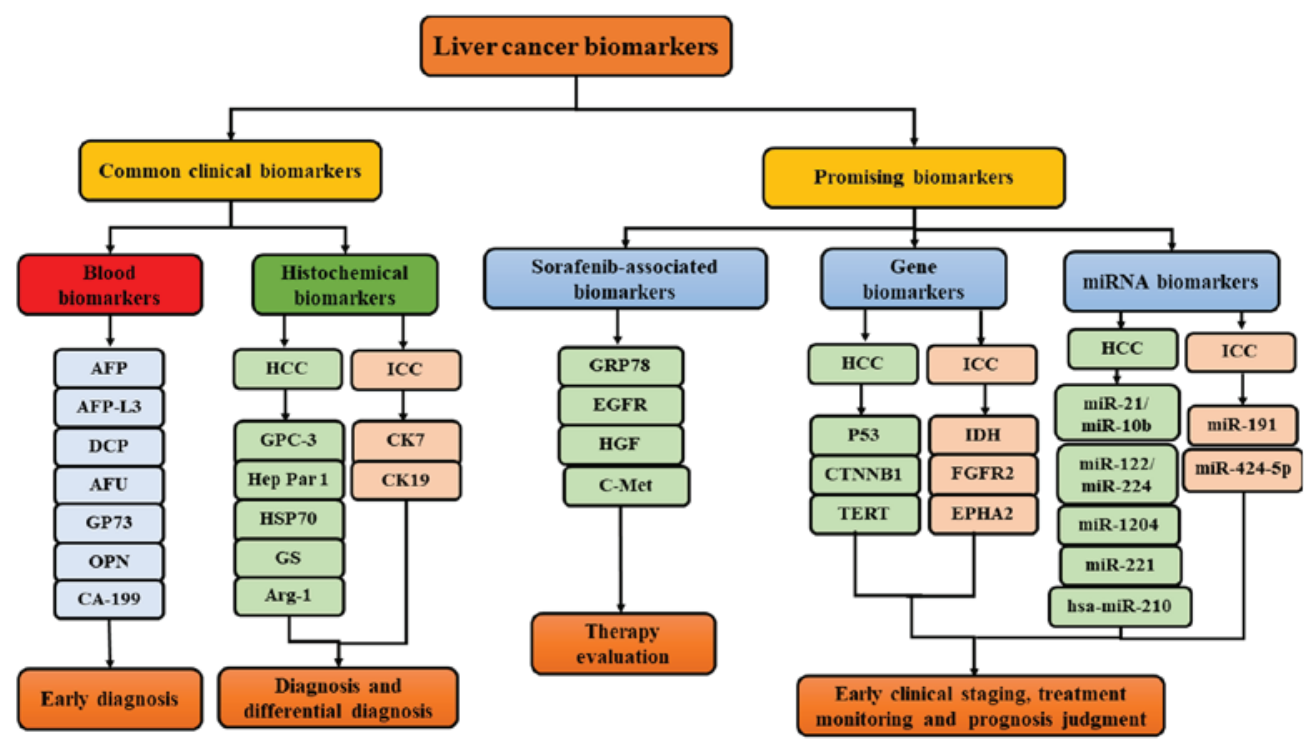

Figure 3. Biomarker profile of primary liver cancer. Liver cancer biomarkers are systematically summarized, and mainly include common clinical biomarkers, resistance-associated biomarkers and promising biomarkers, contributing to the diagnosis, differential diagnosis and treatment of patients with HCC and ICC. HCC, hepatocellular carcinoma; ICC, intrahepatic cholangiocarcinoma.

the diagnosis of well-differentiated small HCC (sHCC) from that of high-grade dysplastic nodules in liver biopsies and surgical specimens (57). A study identified that HSP70 served as the most highly upregulated gene in early HCC tissue sections (58). HSP70 is associated with vascular invasion, high stage, low grade, poor differentiation, cell proliferation, lymph node metastasis, high Ki-67 index and larger tumor size in HCC (59). However, another study reported that the overexpression of HSP70 was associated with portal vein invasion, but could not predict the overall survival of patients with HCC (60).

Glutamine synthetase (GS). GS is an enzyme of nitrogen metabolism that catalyzes the conversion of glutamate and ammonia to glutamine in the liver. GS is expressed in hepatocytes surrounding the terminal hepatic venues under normal conditions, but is diffusely located in hepatocellular tumors $(61,62)$. Glutamine provides energy to tumor cells and so GS is diffusely expressed in HCC; the expression of $\mathrm{HCC}$ is closely associated with $\beta$-catenin gene mutations and the Wnt signaling pathway. GS positivity may imply specific epidemiological and genetic profiles for a subtype of HCC, which includes larger size, low grade, pseudoacini, hydropic changes, bile staining, lack of steatosis, and fibrosis, as well as tumor-specific and overall survival for HCC (62). GS can act as a detector of HCC recurrence, and its upregulation contributes to the increase in metastasis and markedly shorter disease-free survival time in HCC (63). GS and HSP70 positivity are more likely be observed in very well-differentiated HCC than in atypical neoplasms, and may be powerful biomarkers to distinguish between very well-differentiated HCC and atypical cases (64). Strikingly, in a study of cirrhotic and non-cirrhotic livers, the sensitivity of GS was $100 \%$ for HCC in cirrhotic livers, and the specificity was 90\% (65). However, another study reported that HSP70 and GS immunoreactivity did not effectively identify tumor cell origin for ICC (66).
Arginase-1 (Arg-1). Arg-1, an enzyme associated with the hydrolysis of arginine to ornithine and urea, has been observed to be a highly sensitive and specific biomarker for benign and malignant hepatocyte (67). Arg-1 is a powerful immunohistochemical and biomarker for $\mathrm{HCC}$, is an enhancer of zeste homologue 2, and is considered a useful biomarker for hepatocellular differentiation (68-70). Arg-1 has been shown to be a more sensitive biomarker compared with Hep Par 1 in poorly differentiated HCC, as the latter is sometimes expressed in other non-hepatic tumors (69). Similar results in another study showed that Arg-1 had a higher sensitivity than Hep Par 1 for moderately differentiated and poorly differentiated HCC (70). A comparison of different markers using tissue microarray and fine-needle aspiration specimens revealed that Arg-1 is a superior specific biomarker for $\mathrm{HCC}$, and its specificity was $100 \%$ in a large series of surgical cases $(n=1,222)(67)$.

Cytokeratin (CK)7 and CK19. CK7 and CK19 are members of the cytokeratin family, which are intermediate filament proteins that are mainly expressed in epithelial cells and belong to type II (CK1-8) and type I (CK9-20), respectively. CK7 and CK19 are primarily located in pancreatic ducts, mammary gland ducts and liver bile ducts but are absent from hepatocytes (71). Therefore, CK7 and CK19 can be used as immunohistochemical biomarkers to distinguish ICC from HCC (72), as well as biliary epithelial differentiation. A study found that $\mathrm{CK} 7$ and CK19 were highly expressed in patients with ICC, which was closely associated with aggressive tumor phenotypes and adverse OS (73). In addition, compared with the expression of either CK7 or CK19 alone, the CK7/CK19 index was indicated as a superior independent prognostic factor for ICC. The patients with both high CK7 and CK19 expression, heterogeneous high CK7 or CK19 expression, and both low CK7 and CK19 expression had the lowest, intermediate and highest 5-year survival rates, respectively. Furthermore, when combined with the CK7/CK19 index and clinical-pathological 
risk factors, CK7 and CK19 were found to predict OS more accurately than traditional staging systems (73).

In summary, the commonly used hepatocyte markers are Hep Par-1, GPC-3, Arg-1 and GS, and the common bile duct cell biomarkers are CK7 and CK19. A reasonable combination of immunohistochemical biomarkers is needed to differentiate HCC from ICC and primary HCC from metastatic HCC.

\section{Potential biomarkers}

Although classical biomarkers of $\mathrm{HCC}$ have been routinely used, false positive results in their diagnosis of HCC occur, and their sensitivity and specificity are also insufficient. It is urgently necessary to develop more accurate and effective biomarkers for the early clinical staging, treatment monitoring and prognosis judgement of patients with HCC.

Gene biomarkers. The mutation of p53 is highly prevalent in human cancers, but its mutation is not always associated with evidently altered p53 protein expression in HCC (74). However, mutation of p53 is associated with tumor size, differentiation degree, TNM stage and vascular invasion, as well as to poor prognosis, angiogenesis, metastasis and resistance to standard therapies; therefore, the detection of the mutant p53 gene is significant for HCC $(74,75)$. CTNNB1, encoding $\beta$-catenin, not only is one of the more commonly mutated genes for Wnt signaling activation in HCC but also is associated with mutations in telomerase reverse transcriptase (TERT) promoters (76). CTNNB1-mutated HCCs have been found to be well-differentiated, cholestatic, chromosomally stable and almost never steatotic, associated with an improved prognosis compared with other HCCs, and to usually display microtrabecular and/or acinar growth patterns (75). Mutation of TERT frequently occurs in HCC, suggesting that TERT overexpression is a significant risk factor in hepatocarcinogenesis $(75,76)$. TERT upregulation with HCC has been found to be observably associated with intrahepatic metastasis but not markedly associated with other clinicopathological parameters, and therefore may only serve as a crucial prognostic indicator for late intrahepatic metastasis in HCC treated with curative resection (77). Isocitrate dehydrogenase (IDH) is the enzyme responsible for the conversion of isocitrate to $\alpha$-ketoglutarate in the cytosol (IDH1) and mitochondria (IDH2). In one study, IDH1 and IDH2 mutations were observed in $10 \%$ of patients with ICC, were independently associated with a longer time to tumor recurrence after intrahepatic cholangiocarcinoma resection, and also exhibited an association with p53 overexpression in ICC (78). Fibroblast growth factor receptor (FGFR) 2 is a member of the FGFR family that is stimulated by binding with fibroblast growth factors and functions as a serine/threonine kinase by activating the downstream Ras-MAPK-ERK pathway (79). FGFR2 gene fusion has been detected in 10-16\% of ICCs, particularly in younger patients ( $\leq 40$ years) with a non-obvious tendency for female sex; it affects the outcomes of patients with ICC, and contributes to the antitumor activity and manageable safety profile of derazantinib (80). Mutations of EPH receptor A2 (EPHA2), a member of the tyrosine kinase family, have been found to be frequent in ICC and exhibit a close association with lymph node metastasis, poorer differentiation, higher metastatic ability and angiogenesis in patients with ICC (81).

miRNA biomarkers. microRNAs (miRNAs) are endogenously expressed, highly conserved, small, noncoding RNA molecules, which are considered as promising candidates with non-invasive biomarkers for HCC and ICC (Table III). Exosomal miR-21 and miR-10b, hypoxia inducible factor (HIF)- $1 \alpha$ and HIF- $2 \alpha$ are activated via the acidic microenvironment of HCC, which further stimulates HCC cell proliferation, migration and invasion in vivo and in vitro. Furthermore, serum exosomal miR-21 and miR-10b levels exhibit an association with advanced tumor stage and HIF- $1 \alpha$ and HIF- $2 \alpha$ expression, which are also independent prognostic parameters for disease-free survival in early-stage HCC patients (82). A study found that plasma levels of miR-122 were significantly lower in patients with HCC compared with healthy controls and patients with chronic hepatitis $\mathrm{C}$, while the expression of miR-224 was significantly higher (83). Furthermore, miR-122 and miR-224 were both directly associated with AFP, alanine transaminase, aspartate transaminase and alkaline phosphatase levels and the size of the tumor; therefore, they could be considered as noninvasive biomarkers for early diagnosis in the early stage of progressive HCC (83). In another study, miR-1204 levels were observed to be elevated in HCC tissues and cell lines, which promoted cell proliferation in vitro and tumor growth in vivo as well exhibiting an association with malignant clinical features, such as tumor size and advanced TNM stage, and inhibiting apoptosis in vitro (84). hsa-miR-210 has been identified as an independent prognostic factor, which was significantly overexpressed in venous metastasis positive HCC samples and associated with AFP level, pathological grade, TNM stage, tumor stage and vascular invasion (85). Recently, a study showed that miR-221 was upregulated in HCC tissues, cell lines and the blood of patients with HCC, and that miR-221 upregulation was associated with clinical TNM stage, tumor capsular infiltration and poor prognosis. The findings of the study suggested that combined serum miR-221 and AFP detection exhibits an improved performance than either alone for the early diagnosis of HCC (86). In patients with ICC, miR-191 is distinctly elevated in ICC tissue compared with adjacent normal bile duct tissues, and the overexpression of miR-191 has been shown to induce the proliferation, invasion and migration of cholangiocarcinoma cells in vitro and in vivo via the miR-191/TET1/p53 pathway (87). miR-424-5p has been shown to play different roles in the proliferation and metastasis of various tumors, acting as a suppressor or promotor (88). However, miR-424-5p has been found to be frequently downregulated in ICC tissues compared with adjacent normal tissues and in ICC cells compared with normal bile duct cells, with miR-424-5p knockdown inhibiting invasion and migration in ICC by targeting ARK5; therefore, the restoration of miR-424-5p expression has been suggested to be a promising strategy for ICC therapy (88).

\section{Resistance-associated biomarkers}

Sorafenib has been considered the standard of care for patients with advanced unresectable HCC since 2007; however, in a proportion of patients it is ineffective in clinical 
application (89-91). Effective drug resistance biomarkers to guide clinical drug use are lacking. Glucose-regulated protein78 (GRP78) is an immunoglobulin heavy chain binding protein of the HSP70 family. A study found that autoantibodies against GRP78 may be promising diagnostic biomarkers for HCC, particularly when used in conjunction with AFP, with a sensitivity of $71.4 \%$ (90). In an in vitro study, GRP78 was found to increase the acquisition of sorafenib resistance in HCC, and GRP78 knockdown increased the efficacy of sorafenib-mediated cell death (91). Another study demonstrated that secreted GRP78 was associated with epidermal growth factor receptor (EGFR) via the EGFR-SRC-STAT3 signalling pathway, which conferred resistance to sorafenib (92). EGFR is a member of the HER/ErbB family of receptor tyrosine kinases, which is highly expressed in HCCs and associated with aggressive tumors, metastasis and poor patient survival significantly lower than that in patients with nonmetastatic HCC (93). EGFR may serve as a potential predictor of the resistance of HCC cells to sorafenib. A low expression level of EGFR or inhibition of the kinase activity of EGFR has been shown to increase the sensitization of HCC cells to sorafenib (94). EGFR is also overexpressed in ICC, with reported positivity rates ranging from 10 to $80 \%$ (95). Hepatocyte growth factor (HGF) is a member of the peptidase S1 family of serine proteases, and its receptor is c-Met, which is a single-pass tyrosine kinase receptor. c-Met has been observed to be overexpressed in $>80 \%$ of patients with $\mathrm{HCC}$, which is associated with poor prognosis and short survival (96). A study reported that, compared with sorafenib-sensitive HCC, patient specimens of sorafenib-resistant HCC exhibited increased levels of activated p-Met (97). Furthermore, c-Met expression was found to be expressed at markedly high levels in sorafenib-resistant HCC cells compared with their sorafenib-sensitive counterparts, and sorafenib treatment increased the production of HGF and the phosphorylation of c-Met (98). After 10 years of research, there are still no established drug resistance biomarkers to guide the clinical use of sorafenib in HCC. It is possible that the application of omics technology combined with bioinformatics to examine the association between patient outcome and resistance biomarker response to sorafenib could be an alternative approach in finding new biomarkers for HCC (89).

\section{Biomarker-associated signaling pathways}

Biomarker-associated signaling pathways contribute to revealing the mechanism of the occurrence and development of HCC. The present article summarizes the biomarker-associated signaling pathways involved in HCC progression, with a focus on the Wnt signaling pathway, c-Met signaling pathway, phosphatidylinositol 3-kinase (PI3K)/AKT signaling pathway and p53 signaling pathway (Fig. 2).

Wht signaling pathway. Approximately 50\% of HCCs are regulated by the Wnt/Frizzled/ $\beta$-catenin pathway, and Wnt signaling is potentially activated in up to $95 \%$ of HCCs (99). GPC-3 can combine with Wnt and its receptor Frizzled to stimulate the Wnt signaling pathway, which is intimately associated with the nuclear/cytoplasmic localization of $\beta$-catenin (46). The activation of $\beta$-catenin and the aberrant expression of GS have intimate associations in HCC. A study found that a nuclear presence of $\beta$-catenin was associated with GS expression in all tumors, and $84 \%$ of HCCs showed the cytoplasmic presence of $\beta$-catenin associated with GS expression (100). In another study, Wnt activation was detected in HCC tissues and categorized into two subclasses, namely a CTNNB1 class and a Wnt-transforming growth factor (TGF)- $\beta$ class (101). The CTNNB1 class was characterized by CTNNB1 mutations, nuclear $\beta$-catenin positivity, and tumor diameter $>3 \mathrm{~cm}$, while the Wnt-TGF- $\beta$ class was characterized by TGF- $\beta$ activation, cytoplasmic $\beta$-catenin positivity, vascular invasion, satellitosis and an increased risk of early recurrence after surgical resection (101).

c-Met signaling pathway. HGF/c-Met signaling is activated in $\mathrm{HCC}$ and promotes hepatocyte proliferation and regeneration. HGF and c-Met are upregulated in HCC, which is associated with early recurrence, metastasis and worse overall survival, as well as the inhibition of HCC apoptosis which facilitates HCC progression (102). Activation of the DCP-c-Met-Janus kinase 1-STAT3 kinase cascade stimulates HCC growth (13). Furthermore, GPC-3 has been shown to control the migration and motility of HCC cells via heparan sulfate chain-mediated growth combined with the HGF/Met pathway (103).

PI3K/AKT signaling pathway. The PI3K/AKT pathway is frequently activated in human cancer, including HCC, and regulates cell proliferation, metabolism, invasion, metastasis and resistance to various treatments $(104,105)$. Phosphatase and tensin homologue deleted on chromosome 10 (PTEN), an inhibitor of the PI3K/AKT pathway in tumors, is often inactivated in HCC (105). TERT has been demonstrated to influence aberrant DNA methyltransferase 3B expression/aberrant DNA via PTEN downregulation and AKT overexpression to promote HCC development and progression (104). Furthermore, AFP suppresses autophagy and apoptosis and contributes to the promotion of proliferation, migration and invasion in $\mathrm{HCC}$ by interacting with PTEN and activating PI3K/AKT/mTOR signaling (105).

p53 signaling pathway. Mutations of the p53 signaling pathway are common in $\mathrm{HCC}$, and the combination of $\mathrm{p} 53$ with hepatitis B virus X-protein in the cytoplasm has been shown to promote the development of HCC (106). p53 is principally controlled by the E3 ubiquitin ligase murine double minute 2 (MDM2). There is a dynamic balance between MDM2 and p53 in normal conditions, whereas in HCC cells, the balance is destroyed, and MDM2 is overexpressed and p53 is downregulated (106). Furthermore, a study demonstrated that GP73 knockdown promoted the accumulation of intracellular matrix metalloproteinase-2 (MMP2), suppressed MMP2 secretion and further inhibited invasion in HCC cells by inhibiting p53-p21 signaling pathways via a negative feedback loop (26).

\section{Conclusions}

The key to solving the difficulties in the treatment of primary liver cancer mainly lies in early diagnosis and treatment. 
Biomarkers serve an important role in diagnosis, differential diagnosis and prognosis; they enable targeted therapy and also provide benefits for the progress of disease research. Early diagnosis is very important for the prognosis and treatment of patients with liver cancer, and the sensitivity and specificity of tumor biomarkers are of great significance for the early diagnosis of liver cancer. The combined application of several biomarkers is conducive to the early diagnosis of liver cancer. At present, AFP, AFP-L3 and DCP are common serum biomarkers used to diagnose liver cancer earlier in internal and external clinical settings. Recently, numerous studies have investigated novel serum biomarkers, such as AFU, GP73 and OPN, to provide accurate diagnosis and early treatment for patients. The final diagnosis and pathological classification of primary liver cancer have been achieved using H\&E staining and IHC, and confirmed via histochemical biomarkers, including classical biomarkers (GPC-3, Hep Par 1, HSP70, GS, Arg-1, CK7 and CK19). These biomarkers indicate the differentiation degree, histological type, clinicopathological features and prognosis. Furthermore, a number of studies have shown that gene-targeted therapies have a good curative effect. Notably, integrated genomic studies have revealed potential therapeutic targets in HCC and ICC, including CTNNB1 and IDH, respectively. Therefore, genetic biomarkers in patients with liver cancer favor individualized gene-targeted therapy and improve prognosis. In the current review, various tumor biomarkers are summarized in different liver cancers, such as HCC, ICC and cHCC-CC (Fig. 3). Novel tumor biomarkers may be used in clinical practice in the near future, which brings new hope for the early diagnosis and accurate treatment of patients with liver cancer. Targeted drugs are being studied for some biomarkers, and individualized treatment is conducted for patients to improve their quality of life and survival. Further study of biomarker-related signaling pathways will contribute to the deep exploration of the mechanism underlying the occurrence and development of HCC. The development of biotechnology is also prompting researchers to use modern technology to improve the sensitivity of diagnostic biomarkers of HCC to achieve the early diagnosis of HCC, increase the cure rate and reduce mortality.

\section{Acknowledgements}

Not applicable.

\section{Funding}

This review was supported by the National Science and Technology Major Special Program of the 13th Five-Year Plan for the Prevention and Control of Major Infectious Diseases such as AIDS and Viral Hepatitis (grant no. 2018ZX10302205-005), Capital's Funds for Health Improvement and Research (grant no. 2018-1-1151), the National Natural Science Foundation of China (grant no. 81672026) and Beijing Natural Science Foundation (grant no. 7192084).

\section{Availability of data and materials}

Not applicable.

\section{Authors' contributions}

YXG wrote the manuscript, searched literatures and made figures and lists . XNL and DXC provided article ideas, modified the lists and revised the manuscript.. TWY, JMY, PXY, BXK and MYC performed literature research and collected relevant articles. All authors read and approved the final manuscript.

\section{Ethics approval and consent to participate}

Not applicable.

\section{Patient consent for publication}

Not applicable.

\section{Competing interests}

The authors declare that they have no competing interests.

\section{References}

1. Bray F, Ferlay J, Soerjomataram I, Siegel RL, Torre LA and Jemal A: Global cancer statistics 2018: GLOBOCAN estimates of incidence and mortality worldwide for 36 cancers in 185 countries. CA Cancer J Clin 68: 394-424, 2018.

2. Gera S, Ettel M, Acosta-Gonzalez G and Xu R: Clinical features, histology, and histogenesis of combined hepatocellular-cholangiocarcinoma. World J Hepatol 6: 300-309, 2017.

3. Saffroy R, Pham P, Reffas M, Takka M, Lemoine A and Debuire B: New perspectives and strategy research biomarkers for hepatocellular carcinoma. Clin Chem Lab Med 45: 1169-1179, 2007.

4. Zhou YM, Yang JM, Li B, Yin ZF, Xu F, Wang B, Liu P and Li ZM: Clinicopathologic characteristics of intrahepatic cholangiocarcinoma in patients with positive serum a-fetoprotein. World J Gastroenterol 14: 2251-2254, 2008.

5. Yin X, Zhang BH, Qiu SJ, Ren ZG, Zhou J, Chen XH, Zhou Y and Fan J: Combined hepatocellular carcinoma and cholangiocarcinoma: Clinical features, treatment modalities, and prognosis. Ann Surg Oncol 19: 2869-2876, 2012.

6. Yamashita T, Forgues M, Wang W, Kim JW, Ye Q, Jia H, Budhu A, Zanetti KA, Chen Y, Qin LX, et al: EpCAM and alpha-fetoprotein expression defines novel prognostic subtypes of hepatocellular carcinoma. Cancer Res 68: 1451-1461, 2008.

7. Li R, Yang D, Tang CL, Cai P, Ma KS, Ding SY, Zhang XH, Guo DY and Yan XC: Combined hepatocellular carcinoma and cholangiocarcinoma (biphenotypic) tumors: Clinical characteristics, imaging features of contrast-enhanced ultrasound and computed tomography. BMC Cancer 16: 158, 2016.

8. Bertino G, Ardiri A, Malaguarnera M, Malaguarnera G, Bertino N and Calvagno GS: Hepatocellualar carcinoma serum markers. Semin Oncol 39: 410-433, 2012.

9. Hagiwara S, Kudo M, Kawasaki T, Nagashima M, Minami Y, Chung H, Fukunaga T, Kitano $M$ and Nakatani T: Prognostic factors for portal venous invasion in patients with hepatocellular carcinoma. J Gastroenterol 41: 1214-1219, 2006.

10. Tamura Y, Igarashi M, Kawai H, Suda T, Satomura S and Aoyagi Y: Clinical advantage of highly sensitive on-chip immunoassay for fucosylated fraction of alpha-fetoprotein in patients with hepatocellular carcinoma. Dig Dis Sci 55: 3576-3583, 2010.

11. Choi J, Kim GA, Han S, Lee W, Chun S and Lim YS: Longitudinal assessment of three serum biomarkers to detect very early stage hepatocellular carcinoma. Hepatology 69: 1983-1994, 2019.

12. Choi JY, Jung SW, Kim HY, Kim M, Kim Y, Kim DG and Oh EJ: Diagnostic value of AFP-L3 and PIVKA-II in hepatocellular carcinoma according to total-AFP. World J Gastroenterol 19: 339-346, 2013.

13. Taketa K: Alpha-fetoprotein: Reevaluation in hepatology. Hepatology 12: 1420-1432, 1990.

14. Zhang YS, Chu JH, Cui SX, Song ZY and Qu XJ: Des- $\gamma$-carboxy prothrombin (DCP) as a potential autologous growth factor for the development of hepatocellular carcinoma. Cell Physiol Biochem 34: 903-915, 2014. 
15. Hu B, Tian X, Sun J and Meng X: Evaluation of individual and combined applications of serum biomarkers for diagnosis of hepatocellular carcinoma: A meta-analysis. Int J Mol Sci 14: 23559-23580, 2013

16. Volk ML, Hernandez JC, Su GL, Lok AS and Marrero JA: Risk factors for hepatocellular carcinoma may impair the performance of biomarkers: A comparison of AFP, DCP, and AFP-L3. Cancer Biomark 3: 79-87, 2007.

17. Song P, Tobe RG, Inagaki Y, Kokudo N, Hasegawa K, Sugawara Y and Tang W: The management of hepatocellular carcinoma around the world: A comparison of guidelines from 2001 to 2011 Liver Int 32: 1053-1063, 2012.

18. Yamamoto K, Imamura $H$, Matsuyama $Y$, Kume $Y$, Ikeda $H$, Norman GL, Shums Z, Aoki T, Hasegawa K, Beck Y, et al: AFP, AFP-L3, DCP, and GP73 as markers for monitoring treatment response and recurrence and as surrogate markers of clinicopathological variables of HCC. J Gastroenterol 45: 1272-1282, 2010.

19. Chen J, Wu G and Li Y: Evaluation of serum des-gamma-carboxy prothrombin for the diagnosis of hepatitis B virus-related hepatocellular carcinoma: A meta-analysis. Dis Markers 2018: 8906023, 2018

20. Masuzaki R, Karp SJ and Omata M: New serum markers of hepatocellular carcinoma. Semin Oncol 39: 434-439, 2012.

21. Wang K, Guo W, Li N, Shi J, Zhang C, Lau WY, Wu M and Cheng S: Alpha-1-fucosidase as a prognostic indicator for hepatocellular carcinoma following hepatectomy: A large-scale, long-term study. Br J Cancer 110: 1811-1819, 2014.

22. Mintz K, Waidely E, Zhou Y, Peng Z, Al-Youbi AO, Bashammakh AS, El-Shahawi MS and Leblanc RM: Carbon dots and gold nanoparticles based immunoassay for detection of alpha-L-fucosidase. Anal Chim Acta 1041: 114-121, 2018.

23. El-Tayeh SF, Hussein TD, El-Houseini ME, Amer MA, El-Sherbini M and Elshemey WM: Serological biomarkers of hepatocellular carcinoma in Egyptian patients. Dis Markers 32: 255-263, 2012

24. Waidely E, Al-Youbi AO, Bashammakh AS, El-Shahawi MS and Leblanc RM: Alpha-l-fucosidase immunoassay for early detection of hepatocellular carcinoma. Anal Chem 89: 9459-9466, 2017.

25. Wei C, Yang X, Liu N, Geng J, Tai Y, Sun Z, Mei G, Zhou P, Peng Y, Wang C, et al: Tumor microenvironment regulation by the endoplasmic reticulum stress transmission mediator Golgi protein 73 in mice. Hepatology 70: 851-870, 2019.

26. Liu Y, Zhang X, Zhou S, Shi J, Xu Y, He J, Lin F, Wei A, Zhou L and Chen Z: Knockdown of Golgi phosphoprotein 73 blocks the trafficking of matrix metalloproteinase-2 in hepatocellular carcinoma cells and inhibits cell invasion. J Cell Mol Med 23: 2399-2409, 2019

27. Block TM, Comunale MA, Lowman M, Steel LF, Romano PR, FimmelC, Tennant BC,London WT,Evans AA, Blumberg BS, et al: Use of targeted glycoproteomics to identify serum glycoproteins that correlate with liver cancer in woodchucks and humans. Proc Natl Acad Sci USA 102: 779-784, 2005.

28. Mao Y, Yang H, Xu H, Lu X, Sang X, Du S, Zhao H, Chen W, $\mathrm{Xu}$ Y, Chi T, et al: Golgi protein 73 (GOLPH2) is a valuable serum marker for hepatocellular carcinoma. Gut 59: 1687-1693, 2010.

29. Ibrahim GH, Mahmoud MA and Aly NM: Evaluation of circulating transforming growth factor-beta1, glypican-3 and Golgi protein-73 mRNAs expression as predictive markers for hepatocellular carcinoma in Egyptian patients. Mol Biol Rep 40: 7069-7075, 2013.

30. Zhang Z, Zhang Y, Wang Y, Xu L and Xu W: Alpha-fetoprotein-L3 and Golgi protein 73 may serve as candidate biomarkers for diagnosing alpha-fetoprotein-negative hepatocellular carcinoma. Onco Targets Ther 9: 123-129, 2015.

31. Lamort AS, Giopanou I, Psallidas I and Stathopoulos GT: Osteopontin as a link between inflammation and cancer: The thorax in the spotlight. Cells 8: pii: E815, 2019.

32. Ying X, Zhao Y, Wang JL, Zhou X, Zhao J, He CC, Guo XJ, Jin GH, Wang LJ, Zhu Q and Han SX: Serum anti-osteopontin autoantibody as a novel diagnostic and prognostic biomarker in patients with hepatocellular carcinoma. Oncol Rep 32: $1550-1556,2014$.

33. Shang S, Plymoth A, Ge S, Feng Z, Rosen HR, Sangrajrang S, Hainaut P, Marrero JA and Beretta L: Identification of osteopontin as a novel marker for early hepatocellular carcinoma. Hepatology 55: 483-490, 2012

34. Zhu Y, Yang J, Xu D, Gao XM, Zhang Z, Hsu JL, Li CW, Lim SO, Sheng YY, Zhang Y, et al: Disruption of tumour-associated macrophage trafficking by the osteopontin-induced colony-stimulating factor-1 signalling sensitises hepatocellular carcinoma to anti-PD-L1 blockade. Gut 9: 1653-1666, 2019.
35. Liu K, Duan J, Liu H, Yang X, Yang J, Wu M and Chang Y: Precancer antiviral treatment reduces microvascular invasion of early-stage Hepatitis B-related hepatocellular carcinoma. Sci Rep 9: 2220, 2019.

36. Qin XL, Wang ZR, Shi JS, Lu M, Wang L and He QR: Utility of serum CA19-9 in diagnosis of cholangiocarcinoma: In comparison with CEA. World J Gastroenterol 10: 427-432, 2004

37. Minato H, Nakanuma Y and Terada T: Expression of blood group-related antigens in cholangiocarcinoma in relation to non-neoplastic bile ducts. Histopathology 28: 411-419, 1996.

38. Wang Y, Li J, Xia Y, Gong R, Wang K, Yan Z, Wan X, Liu G, Wu D, Shi L, et al: Prognostic nomogram for intrahepatic cholangiocarcinoma after partial hepatectomy. J Clin Oncol 31: 1188-1195, 2013.

39. Yamada T, Nakanishi Y, Okamura K, Tsuchikawa T, Nakamura T, Noji T, Asano T, Tanaka K, Kurashima Y, Ebihara Y, et al: Impact of serum carbohydrate antigen 19-9 level on prognosis and prediction of lymph node metastasis in patients with intrahepatic cholangiocarcinoma. J Gastroenterol Hepatol: Feb 10, 2018 (Epub ahead of print).

40. Carr BI, Kanke F, Wise M and Satomura S: Clinical evaluation of lens culinaris agglutinin-reactive alpha-fetoprotein and des-gamma-carboxy prothrombin in histologically proven hepatocellular carcinoma in the United States. Dig Dis Sci 52: 776-782, 2007.

41. Omata M, Cheng AL, Kokudo N, Kudo M, Lee JM, Jia J, Tateishi R, Han KH, Chawla YK, Shiina S, et al: Asia-Pacific clinical practice guidelines on the management of hepatocellular carcinoma: A 2017 update. Hepatol Int 11: 317-370, 2017.

42. Kokudo N, Hasegawa K, Akahane M, Igaki H, Izumi N, Ichida T, Uemoto S, Kaneko S, Kawasaki S, Ku Y, et al: Evidence-based clinical practice guidelines for hepatocellular carcinoma: The Japan society of hepatology 2013 update (3rd JSH-HCC Guidelines). Hepatol Res 45, 2015.

43. World Health Organization (WHO): Guidelines for the prevention, care and treatment of persons with chronic hepatitis $\mathrm{B}$ infection. WHO, Geneva, 2015.

44. Zhou J, Sun HC, Wang Z, Cong WM, Wang JH, Zeng MS, Yang JM, Bie P, Liu LX, Wen TF, et al: Guidelines for diagnosis and treatment of primary liver cancer in China (2017 Edition). Liver Cancer 7: 235-260, 2018.

45. Nishida T and Kataoka H: Glypican 3-targeted therapy in hepatocellular carcinoma. Cancers (Basel) 11: pii: E1339, 2019.

46. Chen C, Huang X, Ying Z, Wu D, Yu Y, Wang X and Chen C: Can glypican-3 be a disease-specific biomarker? Clin Transl Med 6: 18, 2017.

47. Shirakawa H, Kuronuma T, Nishimura Y, Hasebe T, Nakano M, Gotohda N, Takahashi S, Nakagohri T, Konishi M, Kobayashi N, et al: Glypican-3 is a useful diagnostic marker for a component of hepatocellular carcinoma in human liver cancer. Int J Oncol 34: 649-656, 2009.

48. Capurro M, Wanless IR, Sherman M, Deboer G, Shi W, Miyoshi E and Filmus J: Glypican-3: A novel serum and histochemical marker for hepatocellular carcinoma. Gastroenterology 125: 89-97, 2003.

49. Kolluri A and Ho M: The role of glypican-3 in regulating Wnt, YAP, and hedgehog in liver cancer. Front Oncol 9: 708, 2019.

50. Liu H, Li P, Zhai Y, Qu CF, Zhang LJ, Tan YF, Li N and Ding HG: Diagnostic value of glypican-3 in serum and liver for primary hepatocellular carcinoma. World J Gastroenterol 16: 4410-4415, 2010.

51. Wang L, Yao M, Pan LH, Qian Q and Yao DF: Glypican-3 is a biomarker and a therapeutic target of hepatocellular carcinoma. Hepatobiliary Pancreat Dis Int 14: 361-366, 2015.

52. Han HH, Qiu YJ, Shi YY, Wen W, He XP, Dong LW, Tan YX, Long YT, Tian H and Wang HY: Glypican-3-targeted precision diagnosis of hepatocellular carcinoma on clinical sections with a supramolecular 2D imaging probe. Theranostics 8: 3268-3274, 2018.

53. Kakar S, Muir T, Murphy LM, Lloyd RV and Burgart LJ: Immunoreactivity of Hep Par 1 in hepatic and extrahepatic tumors and its correlation with albumin in situ hybridization in hepatocellular carcinoma. Am J Clin Patho 119: 361-366, 2003.

54. Leong AS, Sormunen RT, Tsui WM and Liew CT: Hep Par 1 and selected antibodies in the immunohistological distinction of hepatocellular carcinoma from cholangiocarcinoma, combined tumours and metastatic carcinoma. Histopathology 33: 318-324, 1998.

55. Ibrahim TR and Abdel-Raouf SM: Immunohistochemical study of glypican-3 and HepPar-1 in differentiating hepatocellular carcinoma from metastatic carcinomas in FNA of the liver. Pathol Oncol Res 21: 379-387, 2015. 
56. Kakar S, Gown AM, Goodman ZD and Ferrell LD: Best practices in diagnostic immunohistochemistry: Hepatocellular carcinoma versus metastatic neoplasms. Arch Pathol Lab Med 131: 1648-1654, 2007.

57. Wang C, Zhang Y, Guo K, Wang N, Jin H, Liu Y and Qin W: Heat shock proteins in hepatocellular carcinoma: Molecular mechanism and therapeutic potential. Int J Cancer 138: 1824-1834, 2016.

58. Chuma M, Sakamoto M, Yamazaki K, Ohta T, Ohki M, Asaka $\mathrm{M}$ and Hirohashi S: Expression profiling in multistage hepatocarcinogenesis: Identification of HSP70 as a molecular marker of early hepatocellular carcinoma. Hepatology 37: 198-207, 2003.

59. Shin E, Ryu HS, Kim SH, Jung H, Jang JJ and Lee K: The clinicopathological significance of heat shock protein 70 and glutamine synthetase expression in hepatocellular carcinoma. J Hepatobiliary Pancreat Sci 18: 544-550, 2011.

60. Kang GH, Lee BS, Lee ES, Kim SH, Lee HY and Kang DY: Prognostic significance of p53, mTOR, c-Met, IGF-1R, and HSP70 overexpression after the resection of hepatocellular carcinoma. Gut Liver 8: 79-87, 2014.

61. Evason KJ, Grenert JP, Ferrell LD and Kakar S: Atypical hepatocellular adenoma-like neoplasms with $\beta$-catenin activation show cytogenetic alterations similar to well-differentiated hepatocellular carcinomas. Hum Pathol 44: 750-758, 2013.

62. Dal Bello B, Rosa L, Campanini N, Tinelli C, Torello Viera F, D'Ambrosio G, Rossi S and Silini EM: Glutamine synthetase immunostaining correlates with pathologic features of hepatocellular carcinoma and better survival after radiofrequency thermal ablation. Clin Cancer Res 16: 2157-2166, 2010.

63. Osada T, Nagashima I, Tsuno NH, Kitayama J and Nagawa H: Prognostic significance of glutamine synthetase expression in unifocal advanced hepatocellular carcinoma. J Hepatol 33: 247-253, 2000

64. Nguyen TB, Roncalli M, Di Tommaso L and Kakar S: Combined use of heat-shock protein 70 and glutamine synthetase is useful in the distinction of typical hepatocellular adenoma from atypical hepatocellular neoplasms and well-differentiated hepatocellular carcinoma. Mod Pathol 29: 283-292, 2016.

65. Uthamalingam P, Das A, Behra A, Kalra N and Chawla Y: Diagnostic value of glypican3, heat shock protein 70 and glutamine synthetase in hepatocellular carcinoma arising in cirrhotic and non-cirrhotic livers. J Clin Exp Hepatol 8: 173-180, 2018

66. Lagana SM, Moreira RK, Remotti HE and Bao F: Glutamine synthetase, heat shock protein-70, and glypican-3 in intrahepatic cholangiocarcinoma and tumors metastatic to liver. Appl Immunohistochem Mol Morphol 21: 254-257, 2013.

67. Timek DT, Shi J, Liu H and Lin F: Arginase-1, HepPar-1, and Glypican-3 are the most effective panel of markers in distinguishing hepatocellular carcinoma from metastatic tumor on fine-needle aspiration specimens. Am J Clin Pathol 138: 203-210, 2012.

68. Pesce JT, Ramalingam TR, Mentink-Kane MM, Wilson MS, El Kasmi KC, Smith AM, Thompson RW, Cheever AW, Murray PJ and Wynn TA: Arginase-1-expressing macrophages suppress Th2 cytokine-driven inflammation and fibrosis. PLoS Pathog 5: e1000371, 2009.

69. Fujiwara M, Kwok S, Yano H and Pai RK: Arginase-1 is a more sensitive marker of hepatic differentiation than HepPar-1 and glypican-3 in fine-needle aspiration biopsies. Cancer Cytopathol 120: 230-237, 2012

70. Yan BC, Gong C, Song J, Krausz T, Tretiakova M, Hyjek E, Al-Ahmadie H, Alves V, Xiao SY, Anders RA and Hart JA: Arginase-1: A new immunohistochemical marker of hepatocytes and hepatocellular neoplasms. Am J Surg Pathol 34: 1147-1154, 2010.

71. Moll R, Divo M and Langbein L: The human keratins: Biology and pathology. Histochem Cell Biol 129: 705-733, 2008

72. Ryu HS, Lee K, Shin E, Kim SH, Jing J, Jung HY, Lee H and Jang JJ: Comparative analysis of immunohistochemical markers for differential diagnosis of hepatocelluar carcinoma and cholangiocarcinoma. Tumori 98: 478-484, 2012.

73. Liu LZ, Yang LX, Zheng BH, Dong PP, Liu XY, Wang ZC, Zhou J, Fan J, Wang XY and Gao Q: CK7/CK19 index: A potential prognostic factor for postoperative intrahepatic cholangiocarcinoma patients. J Surg Oncol 117: 1531-1539, 2018.

74. Pinato DJ, Pirisi M, Maslen L and Sharma R: Tissue biomarkers of prognostic significance in hepatocellular carcinoma. Adv Anat Pathol 21: 270-284, 2014.
75. Calderaro J, Couchy G, Imbeaud S, Amaddeo G, Letouzé E, Blanc JF, Laurent C, Hajji Y, Azoulay D, Bioulac-Sage P, et al: Histological subtypes of hepatocellular carcinoma are related to gene mutations and molecular tumour classification. J Hepatol 67: 727-738, 2017.

76. Totoki Y, Tatsuno K, Covington KR, Ueda H, Creighton CJ, Kato M, Tsuji S, Donehower LA, Slagle BL, Nakamura H, et al: Trans-ancestry mutational landscape of hepatocellular carcinoma genomes. Nat Genet 46: 1267-1273, 2014.

77. Yu JI, Choi C, Ha SY, Park CK, Kang SY, Joh JW, Paik SW, Kim S, Kim M, Jung SH and Park HC: Clinical importance of TERT overexpression in hepatocellular carcinoma treated with curative surgical resection in HBV endemic area. Sci Rep 7: 12258, 2017.

78. Wang P, Dong Q, Zhang C, Kuan PF, Liu Y, Jeck WR, Andersen JB, Jiang W, Savich GL, Tan TX, et al: Mutations in isocitrate dehydrogenase 1 and 2 occur frequently in intrahepatic cholangiocarcinomas and share hypermethylation targets with glioblastomas. Oncogene 32: 3091-3100, 2013.

79. Xu YF, Liu HD, Liu ZL, Pan C, Yang XQ, Ning SL, Zhang ZL, Guo $\mathrm{S}$ and $\mathrm{Yu}$ JM: Sprouty2 suppresses progression and correlates to favourable prognosis of intrahepatic cholangiocarcinoma via antagonizing FGFR2 signalling. J Cell Mol Med 22: 5596-5606, 2018

80. Mazzaferro V, El-Rayes BF, Droz Dit Busset M, Cotsoglou C, Harris WP, Damjanov N, Masi G, Rimassa L, Personeni N, Braiteh F, et al: Derazantinib (ARQ 087) in advanced or inoperable FGFR2 gene fusion-positive intrahepatic cholangiocarcinoma. Br J Cancer 120: 165-171, 2019.

81. Sheng Y, Wei J, Zhang Y, Gao X, Wang Z, Yang J, Yan S, Zhu Y, Zhang Z, Xu D, et al: Mutated EPHA2 is a target for combating lymphatic metastasis in intrahepatic cholangiocarcinoma. Int J Cancer 144: 2440-2452, 2019.

82. Tian XP, Wang CY, Jin XH, Li M, Wang FW, Huang WJ, Yun JP, $\mathrm{Xu} \mathrm{RH}, \mathrm{Cai} \mathrm{QQ}$ and Xie D: Acidic microenvironment up-regulates exosomal miR-21 and miR-10b in early-stage hepatocellular carcinoma to promote cancer cell proliferation and metastasis. Theranostics 9: 1965-1979, 2019.

83. Amr KS, Elmawgoud Atia HA, Elazeem Elbnhawy RA and Ezzat WM: Early diagnostic evaluation of miR-122 and miR-224 as biomarkers for hepatocellular carcinoma. Genes Dis 4: 215-221, 2017.

84. Wang L, Sun L, Wang Y, Yao B, Liu R, Chen T, Tu K, Liu Q and Liu Z: MiR-1204 promotes hepatocellular carcinoma progression through activating MAPK and c-Jun/AP1 signaling by targeting ZNF418. Int J Biol Sci 15: 1514-1522, 2019.

85. Ji J, Rong Y, Luo CL, Li S, Jiang X, Weng H, Chen H, Zhang WW, Xie W and Wang FB: Up-regulation of hsa-miR-210 promotes venous metastasis and predicts poor prognosis in hepatocellular carcinoma. Front Oncol 8: 569, 2018

86. Li F, Wang F, Zhu C, Wei Q, Zhang T and Zhou YL: MiR-221 suppression through nanoparticle-based miRNA delivery system for hepatocellular carcinoma therapy and its diagnosis as a potential biomarker. Int J Nanomedicine 13: 2295-2307, 2018

87. Li H, Zhou ZQ, Yang ZR, Tong DN, Guan J, Shi BJ, Nie J, Ding XT, Li B, Zhou GW and Zhang ZY: MicroRNA-191 acts as a tumor promoter by modulating the TET1-p53 pathway in intrahepatic cholangiocarcinoma. Hepatology 66: 136-151, 2017.

88. Wu J, Yang B, Zhang Y, Feng X, He B, Xie H, Zhou L, Wu J and Zheng S: MiR-424-5p represses the metastasis and invasion of intrahepatic cholangiocarcinoma by targeting ARK5. Int J Biol Sci 15: 1591-1599, 2019.

89. Marisi G, Cucchetti A, Ulivi P, Canale M, Cabibbo G, Solaini L, Foschi FG, De Matteis S, Ercolani G, Valgiusti M, et al: Ten years of sorafenib in hepatocellular carcinoma: Are there any predictive and/or prognostic markers. World J Gastroenterol 24: 4152-4163, 2018.

90. Shao Q, Ren P, Li Y, Peng B, Dai L, Lei N, Yao W, Zhao G, Li L and Zhang J: Autoantibodies against glucose-regulated protein 78 as serological diagnostic biomarkers in hepatocellular carcinoma. Int J Oncol 41: 1061-1067, 2012.

91. Chiou JF, Tai CJ, Huang MT, Wei PL, Wang YH, An J, Wu CH, Liu TZ and Chang YJ: Glucose-regulated protein 78 is a novel contributor to acquisition of resistance to sorafenib in hepatocellular carcinoma. Ann Surg Oncol 17: 603-612, 2010.

92. Li R, Yanjiao G, Wubin H, Yue W Jianhua H, Huachuan Z, Rongjian S and Zhidong L: Secreted GRP78 activates EGFR-SRC-STAT3 signaling and confers the resistance to sorafeinib in HCC cells. Oncotarget 8: 19354-19364, 2017. 
93. Hu H, Gao L, Wang C, Li Y, Ma H, Chen L, Qin J,Liu B, Liu Y and Liang C: Lower serum soluble-EGFR is a potential biomarker for metastasis of HCC demonstrated by $\mathrm{N}$-glycoproteomic analysis. Discov Med 19: 333-341, 2015.

94. Ezzoukhry Z, Louandre C, Trécherel E, Godin C, Chauffert B, Dupont S, Diouf M, Barbare JC, Mazière JC and Galmiche A: EGFR activation is a potential determinant of primary resistance of hepatocellular carcinoma cells to sorafenib. Int J Cancer 131: 2961-2969, 2012

95. Komposch K and Sibilia M: EGFR signaling in liver diseases. Int J Mol Sci 17: pii: E30, 2015.

96. Firtina Karagonlar Z, Koc D, Iscan E, Erdal E and Atabey N: Elevated hepatocyte growth factor expression as an autocrine c-Met activation mechanism in acquired resistance to sorafenib in hepatocellular carcinoma cells. Cancer Sci 107: 407-416, 2016.

97. Xiang Q, Chen W, Ren M, Wang J, Zhang H, Deng DY, Zhang L, Shang $\mathrm{C}$ and Chen Y: Cabozantinib suppresses tumor growth and metastasis in hepatocellular carcinoma by a dual blockade of VEGFR2 and MET. Clin Cancer Res 20: 2959-2970, 2014.

98. Han P, Li H, Jiang X, Zhai B, Tan G, Zhao D, Qiao H, Liu B, Jiang $H$ and Sun $X$ : Dual inhibition of Akt and c-Met as a second-line therapy following acquired resistance to sorafenib in hepatocellular carcinoma cells. Mol Oncol 11: 320-334, 2017.

99. Capurro M, Martin T, Shi W and Filmus J: Glypican-3 binds to Frizzled and plays a direct role in the stimulation of canonical Wnt signaling. J Cell Sci 127: 1565-1575, 2014.

100. Austinat M, Dunsch R, Wittekind C, Tannapfel A, Gebhardt R and Gaunitz F: Correlation between beta-catenin mutations and expression of Wnt-signaling target genes in hepatocellular carcinoma. Mol Cancer 7: 21, 2008.
101. Lachenmayer A, Alsinet C, Savic R, Cabellos L, Toffanin S, Hoshida Y, Villanueva A, Minguez B, Newell P, Tsai HW, et al: Wnt-pathway activation in two molecular classes of hepatocellular carcinoma and experimental modulation by sorafenib. Clin Cancer Res 18: 4997-5007, 2012.

102. Hu CT, Wu JR, Cheng CC and Wu WS: The therapeutic targeting of HGF/c-Met signaling in hepatocellular carcinoma: Alternative approaches. Cancers (Basel) 9: pii: E58, 2017.

103. Gao W, Kim Hand Ho M: Human monoclonal antibody targeting the heparan sulfate chains of glypican-3 inhibits HGF-mediated migration and motility of hepatocellular carcinoma cells. PLoS One 10: e0137664, 2015.

104. Yu J, Yuan X, Sjöholm L, Liu T, Kong F, Ekström TJ, Björkholm $\mathrm{M}$ and Xu D: Telomerase reverse transcriptase regulates DNMT3B expression/aberrant DNA methylation phenotype and AKT activation in hepatocellular carcinoma. Cancer Lett 434: 33-41, 2018.

105. Wang S, Zhu M, Wang Q, Hou Y, Li L, Weng H, Zhao Y, Chen D, Ding H, Guo J, Li M. Alpha-fetoprotein inhibits autophagy to promote malignant behaviour in hepatocellular carcinoma cells by activating PI3K/AKT/mTOR signaling. Cell Death Dis 10: 83, 2019.

106. Meng X, Franklin DA, Dong J and Zhang Y: MDM2-p53 pathway in hepatocellular carcinoma. Cancer Res 74: 7161-7167, 2014. 